\title{
Expression and clinical significance of programmed death-1 on lymphocytes and programmed death ligand-1 on monocytes in the peripheral blood of patients with cervical cancer
}

\author{
YING ZHANG $^{1}$, WEIPEI ZHU ${ }^{1}$, XUEGUANG ZHANG ${ }^{2}$, QIUXIA QU ${ }^{2}$ and LIYUAN ZHANG ${ }^{3}$ \\ ${ }^{1}$ Department of Obstetrics and Gynecology, The Second Affiliated Hospital of Soochow University, \\ Suzhou, Jiangsu 215004; ${ }^{2}$ Research Institute of Immunology, Soochow University, Suzhou, Jiangsu 215000; \\ ${ }^{3}$ Department of Radiology, The Second Affiliated Hospital of Soochow University, Suzhou, Jiangsu 215004, P.R. China
}

Received September 24, 2015; Accepted March 17, 2017

DOI: $10.3892 / \mathrm{ol} .2017 .7105$

\begin{abstract}
The programmed death-1 (PD-1) signaling pathway serves a critical role in immune regulation and tolerance by suppressing the activation and proliferation of $\mathrm{T}$ cells. The aim of the present study was to investigate the effect of PD-1 and programmed death-ligand 1 (PD-L1) on the development of cervical carcinoma and cervical intraepithelial neoplasia (CIN). A total of 40 healthy controls (HC), 40 patients with CIN and 66 newly diagnosed cervical cancer patients were recruited. The expression level of PD-1 expression on peripheral cluster of differentiation $(\mathrm{CD}) 4^{+}$and $\mathrm{CD} 8^{+} \mathrm{T}$ cells and PD-L1 on monocytes was analyzed by flow cytometry. The expression level of soluble PD-L1 in serum was determined by an ELISA. The results of the present study demonstrated that the PD- 1 expression level on $\mathrm{CD}^{+}$and $\mathrm{CD} 8^{+} \mathrm{T}$ cells was significantly increased in CIN and cervical cancer, compared with that in HC. In addition, the PD-1 expression level on $\mathrm{CD}^{+}$and $\mathrm{CD}^{+} \mathrm{T}$ cells was increased in cervical cancer, compared with that in CIN. However, the expression level of PDL-1 on CD14 ${ }^{+}$monocytes was increased in cancer and CIN, but limited in cancer and CIN. In addition, PD-1 expression on $\mathrm{CD}^{+} \mathrm{T}$ cells was positively associated with PD-1 expression on $\mathrm{CD}^{+} \mathrm{T}$ cells in cervical cancer $(\mathrm{P}<0.05)$. Further analyses revealed that the proportion of $\mathrm{PD}-1$ on $\mathrm{CD}^{+}$and $\mathrm{CD}^{+}$ $\mathrm{T}$ cells were positively associated with tumor stages. However, no difference in the degree of soluble PD-1 among cancer, CIN and $\mathrm{HC}$ cells was revealed. The results suggested that the PD-1
\end{abstract}

Correspondence to: Professor Weipei Zhu, Department of Obstetrics and Gynecology, The Second Affiliated Hospital of Soochow University, 1055 Sanxiang Road, Suzhou, Jiangsu 215004, P.R. China

E-mail: zwp333xx@163.com

Key words: programmed death-1, programmed death-1 ligand, cervical cancer, $\mathrm{T}$ cells, monocytes signaling pathway is involved in the development of CIN and cervical cancer.

\section{Introduction}

Cervical cancer is the second most common cause of cancer in females worldwide, with $\sim 510,000$ new cases and 288,000 mortalities reported annually (1). Although there have been advances in the diagnosis and prognosis of cervical cancer in previous decades, there is still a requirement to improve early detection screening methods and to identify additional circulating biomarkers for a greater number of patients and more personalized treatments.

The immune system offers an attractive research area to identify novel diagnostic and prognostic markers. Nedergaard et al (2) demonstrated significantly lower peritumoral and intratumoral densities of cluster of differentiation (CD) $4^{+}$and $\mathrm{CD}^{+}$in patients with stage Ib squamous cell cervical carcinoma who had a relapse compared with those who had not. These results suggested that the immune system serves an important role in cervical cancer, and that cells and molecules involved in the regulation of $\mathrm{T}$ cell responses may be novel diagnostic and/or prognostic markers, and therapeutic target for the disease.

The programmed death-1 (PD-1) signaling pathway, an important co-inhibitory pathway, serves a pivotal role in immune regulation and immune tolerance. PD-1/programmed death-ligand 1 (PD-L1) interactions have been revealed to inhibit a wide range of immune responses against pathogens, tumors and self-antigens $(3,4)$. PD-1 (also termed CD279) is expressed on numerous types of cells, including activated $\mathrm{T}$ cells, B cells and natural killer $\mathrm{T}$ (NKT). The associated ligand PD-L1 exhibits a broad expression pattern on a range of leucocytes, non-hematopoietic cells and in non-lymphoid tissues (5). In malignant tumors, the PD-1/PD-L1 signaling pathway participates in immunotolerance and negatively controls antigen-specific T-cell activity via the T-cell receptor and major histocompatibility complex (6). Cancer cells expressing PD-1 ligands (PD-L1/2) inhibit activation of tumor-infiltrating lymphocytes, facilitating disease progression (7-10). Furthermore, previous studies have suggested that 
the upregulation of PD-1/PD-L1 expression level on peripheral blood cells is closely associated with cancer (10-12) and the soluble form of PD-L1 (sPD-L1) may effectively inhibit the proliferation of PD-1 $1^{+} \mathrm{T}$ cells (13). An increased expression level of PD-L1 in patients with lung cancer was closely associated with lymph node metastasis (14). Preliminary clinical trials exploring the interruption of the PD-1/PD-L1 signaling pathway demonstrated a potential antitumor effect in various solid neoplasms, including malignant melanoma, non-small cell lung carcinoma and renal cell carcinoma (15). A previous study reported that PD-L1 is expressed only on a minority of cervical cancer cells and PD-1 is expressed by a large number of infiltrating $\mathrm{CD}^{+} \mathrm{T}$ cells, suggesting that inhibition of PD-1 may have therapeutic potential in patients with cervical cancer (16). Another recent investigation revealed that an aberrant differentiation and accumulation of CD14 ${ }^{+} \mathrm{PD}-\mathrm{L1}^{+}$ M2-macrophage-like cells in the microenvironment of cervical cancer may promote immunosuppressive conditions and were associated with tumor invasion, angiogenesis and metastasis (17). However, the roles of PD-1/PD-L1 on circulating immune cells and SPD-L1 in cervical cancer remain unclear.

The present study aimed to determine the expression levels of PD-1 on $\mathrm{CD}_{4}^{+}$and $\mathrm{CD} 8^{+} \mathrm{T}$ cells and PD-L1 on CD14 monocytes in peripheral blood, and the expression level of sPD-L1 in the serum of patients with cervical carcinoma, and to explore their clinical implications.

\section{Materials and methods}

Study subject recruitment. The present study included 66 patients (age 32-68 years, mean 47.8 years) with FIGO stages I-II cervical carcinoma (18), 40 patients with cervical intraepithelial neoplasia (CIN; age 30-68 years, mean 44.4 years) and 40 healthy controls ( $\mathrm{HC}$; age 34-70 years, mean 48.3 years) admitted to the Department of Obstetrics and Gynecology, The Second Affiliated Hospital of Soochow University (Suzhou, China). The complete date range for patient recruitment was from August 2014 to August 2015. All patients had been histologically diagnosed by the preoperative endoscopy biopsy and the postoperative biopsy diagnosis, and had not received chemotherapy, hormonotherapy, targeted therapy or radiotherapy within the last 6 months. The clinical stages were determined according to the FIGO standard. The clinical characteristics of patients are summarized in Table I. The HCs were recruited from people who came to the same hospital for general health exams. Written informed consent was obtained from all patients or a legally authorized representative prior to blood sampling. The present study was approved by the Ethics Committee of the Second Affiliated Hospital of Soochow University.

Blood sample collection. Blood samples were obtained by venipuncture of the left upper limb on first admission prior to any treatment at fasting state in the morning and stored in sterile tubes that contained EDTA salt and aprotinin. Tubes of peripheral blood were transported to the research center within $12 \mathrm{~h}$ for the determination of expression levels of PD-1 and PD-L1. Subsequently, the supernatant was separated by centrifugation (Centrifuge LDZ5-2; Jinli Centrifuge Co., Ltd.,
Beijing, China) at $1,000 \times \mathrm{g}$ for $15 \mathrm{~min}$ and stored in a $-80^{\circ} \mathrm{C}$ refrigerator until further analysis.

Staining and flow cytometry. The frequencies of PD-1 and PD-L1 expressions were assessed using a Beckman Coulter flow cytometer (FC500; Beckman Coulter, Inc., Brea, CA, USA) in all studied individuals according to the stain-lyse and wash protocol as previously described by Moniuszko et al (19). Briefly, $50 \mu$ EDTA-anti-coagulated whole blood was stained with $5 \mu \mathrm{l}$ of the following mouse anti-human monoclonal antibodies, CD4 fluorescein isothiocyanate (FITC; cat no. 317408), CD8a-FITC (cat no. 301006), CD14-FITC (cat no. 325604), PD-1-phycoerythrin (PE; cat no. 329906) and PD-L1-PE (cat no. 329706$)$ to identify PD $-1^{+} \mathrm{CD} 4^{+}, \mathrm{PD}-1^{+} \mathrm{CD} 8^{+} \mathrm{T}$ cells and $\mathrm{CD} 14^{+} \mathrm{PD}-\mathrm{L1}^{+}$monocytes, respectively (all used as supplied and obtained from BioLegend, Inc., San Diego, CA, USA). All blood samples were incubated for $30 \mathrm{~min}$ at $4^{\circ} \mathrm{C}$ in the dark. Thereafter, the cells were lysed using Optilyse C Lysis Solution (Immotech SAS, Marseille, MC, France) and washed twice with cold PBS. A minimum of 100,000 events was acquired. FlowJo version 7.6.1 (Tree Star, Inc., Ashland, OR, USA) software was used for the analysis of flow cytometry data.

ELISA. ELISA was used to detect PD-L1 in the serum of patients with cervical cancer, CIN and in the HCs. Human sPD-L1 detection kits (Bright Scistar Biotechnology Co., Ltd., Suzhou, China) were used, according to the manufacturer's protocol. The 96-well plate was pre-coated with monoclonal capture antibody [mouse anti-human PD-L1 monoclonal antibody (2H11); cat no. XGKX20150602-1; Bright Scistar Biotechnology Co., Ltd.]. Serum samples were diluted 1:1 with sample diluting buffer (PBS containing $1 \%$ bovine serum albumin, purchased from Sinopharm Chemical Reagent Co., Ltd., Shanghai, China). Equal amounts $(100 \mu \mathrm{l})$ of the standards (recombinant human PD-L1 Fc chimera protein, purchased from R\&D Systems, Inc., Minneapolis, MN, USA) and diluted serum samples were dispensed into the wells of a 96-well plate and incubated for $2 \mathrm{~h}$ at room temperature. Wells were washed with PBST (0.1\% Tween-20 in PBS) three times and $100 \mu \mathrm{l}$ detection antibody [mouse anti-human PD-L1 monoclonal antibody (10D7-Biotin); cat no. XGKX20150602-1; dilution 1:2,000; Bright Scistar Biotechnology Co., Ltd.] was added. The plates were incubated for $1 \mathrm{~h}$ at room temperature, washed with PBST three times, and then further incubated with $100 \mu$ l diluted streptavidin-horseradish peroxidase (cat no. SLBR2968V; dilution 1:6,000; Sigma-Aldrich; Merck KGaA, Darmstadt, Germany) for $45 \mathrm{~min}$ at room temperature. Following eight washes with PBST, $100 \mu$ l chromogenic substrate (TMB blue substrate) was added for another $15 \mathrm{~min}$ at room temperature. The reaction was stopped with $50 \mu \mathrm{l}$ of $2 \mathrm{M}$ sulfuric acid and absorbance was read at $450 \mathrm{~nm}$ by an automated plate reader (Multiskan MK3; Thermo Fisher Scientific, Inc., Waltham, MA, USA). All samples were analyzed in duplicate and standard curves were run for each plate.

Statistical analysis. All statistical analyses were performed using GraphPad Prism version 5.0 (GraphPad Software, Inc., La Jolla, CA, USA). An unpaired Student's t-test was used 
Table I. Association between the expression levels of PD-1 on T cells and PD-L1 on monocytes and clinicopathological factors in cervical carcinoma.

\begin{tabular}{|c|c|c|c|c|c|c|c|}
\hline Parameter & $\mathrm{n}$ & $\begin{array}{l}\mathrm{PD}-1^{+} \mathrm{CD} 4^{+} \\
\mathrm{T} \text { cells }(\%)\end{array}$ & P-value & $\begin{array}{l}\mathrm{PD}-1^{+} \mathrm{CD} 8^{+} \\
\mathrm{T} \text { cells }(\%)\end{array}$ & P-value & $\begin{array}{l}\text { PD-L1+CD } 14^{+} \\
\text {monocytes }(\%)\end{array}$ & P-value \\
\hline Age, years & & & $>0.05$ & & $>0.05$ & & $>0.05$ \\
\hline$<50$ & 38 & $42.93 \pm 2.02$ & & $33.25 \pm 1.93$ & & $73.69 \pm 3.16$ & \\
\hline$\geq 50$ & 28 & $40.39 \pm 2.47$ & & $30.59 \pm 2.10$ & & $70.06 \pm 4.56$ & \\
\hline Histopathology & & & $>0.05$ & & $>0.05$ & & $>0.05$ \\
\hline $\mathrm{SCC}$ & 58 & $42.00 \pm 1.64$ & & $32.88 \pm 1.54$ & & $73.17 \pm 1.71$ & \\
\hline $\mathrm{ADC} / \mathrm{ADSC}$ & 8 & $40.80 \pm 5.36$ & & $25.54 \pm 1.53$ & & $65.60 \pm 8.32$ & \\
\hline FIGO stage & & & $<0.05$ & & $<0.05$ & & $>0.05$ \\
\hline Stage I & 35 & $38.71 \pm 2.09$ & & $30.97 \pm 1.94$ & & $73.13 \pm 3.23$ & \\
\hline Stage II & 31 & $42.28 \pm 2.25$ & & $33.30 \pm 2.05$ & & $71.49 \pm 4.19$ & \\
\hline Grade of differentiation & & & $>0.05$ & & $>0.05$ & & $>0.05$ \\
\hline Good & 14 & $39.13 \pm 2.55$ & & $28.61 \pm 3.14$ & & $72.55 \pm 4.14$ & \\
\hline Moderate/poor & 42 & $41.08 \pm 4.39$ & & $30.33 \pm 1.89$ & & $69.83 \pm 1.74$ & \\
\hline Lymph nodes & & & $>0.05$ & & $>0.05$ & & $>0.05$ \\
\hline Negative & 58 & $42.19 \pm 1.57$ & & $32.95 \pm 1.49$ & & $73.18 \pm 2.65$ & \\
\hline Positive & 8 & $39.31 \pm 6.67$ & & $24.93 \pm 3.32$ & & $65.49 \pm 10.10$ & \\
\hline Tumor size, mm & & & $>0.05$ & & $>0.05$ & & $>0.05$ \\
\hline$<40$ & 34 & $39.62 \pm 1.99$ & & $32.66 \pm 1.84$ & & $71.25 \pm 3.51$ & \\
\hline$\geq 40$ & 32 & $44.36 \pm 2.38$ & & $31.46 \pm 2.28$ & & $73.55 \pm 3.87$ & \\
\hline Parametrical invasion & & & $>0.05$ & & $>0.05$ & & $>0.05$ \\
\hline Without & 59 & $46.03 \pm 1.62$ & & $33.05 \pm 1.48$ & & $73.15 \pm 2.62$ & \\
\hline With & 7 & $40.37 \pm 6.20$ & & $27.60 \pm 1.96$ & & $64.48 \pm 11.60$ & \\
\hline HR-HPV & & & $>0.05$ & & $>0.05$ & & $>0.05$ \\
\hline Negative & 15 & $40.98 \pm 1.34$ & & $31.47 \pm 2.08$ & & $70.16 \pm 5.67$ & \\
\hline Positive & 51 & $43.55 \pm 2.65$ & & $31.99 \pm 1.77$ & & $72.98 \pm 4.10$ & \\
\hline
\end{tabular}

Data are presented as the mean \pm standard deviation. All statistical analyses were conducted using GraphPad Prism 5.0 (GraphPad Software, Inc., San Diego, CA, USA) and an unpaired Student's t-test was used for comparison between groups. FIGO, International Federation of Gynecology and Obstetrics; SCC, squamous cell carcinoma; ADC, adenocarcinoma; ADSC, adenosquamous carcinoma; HR-HPV, high-risk type of human papillomavirus.

for comparison between groups. The Pearson's correlation analysis was used to determine the correlation coefficient. The data are expressed as the mean \pm standard deviation. $\mathrm{P}<0.05$ (two-tailed) was considered to indicate a statistically significant difference.

\section{Results}

PD-1 and PD-L1 expression levels increased on peripheral $T$ cells and $C D 14^{+}$monocytes, respectively. The expression levels of PD-1 on lymphocytes and PD-L1 on monocytes were detected in peripheral blood of 66 patients with cervical cancer, 36 patients with CIN and $31 \mathrm{HCs}$. Patients and controls did not exhibit any significant difference with regard to age $(\mathrm{P}>0.05)$. The PD-1 expression level on $\mathrm{CD}^{+}$and $\mathrm{CD}^{+}$ $\mathrm{T}$ cells was significantly increased in $\mathrm{CIN}$ and cervical cancer, compared with that in HC. In addition, the PD-1 expression level on $\mathrm{CD}^{+}$and $\mathrm{CD}^{+} \mathrm{T}$ cells was increased in cervical cancer, compared with that in CIN. However, the expression level of PDL-1 on CD14 ${ }^{+}$monocytes was increased in cancer and CIN, but limited in cancer and CIN (Figs. 1 and 2). The results of the present study indicated that in addition to PD-1 upregulation on T cells, PD-L1 expression level on monocytes also increased significantly in cervical lesions suggesting that the PD-1/PD-L1 signaling pathway may be involved in the pathogenesis of cervical cancer and CIN by its regulation on circulating immune cells. The present study further investigated the associations amongst these subsets. The data revealed that PD-1 expression on $\mathrm{CD}^{+} \mathrm{T}$ cells was positively associated with $\mathrm{PD}-1$ expression on $\mathrm{CD}^{+} \mathrm{T}$ cells in cancer $(\mathrm{r}=0.43 ; \mathrm{P}<0.001)$; however, no correlation was identified between PD-1 and PD-L1 expression levels (Fig. 3).

The associations of clinicopathological factors with PD-1 and PD-L1 expression. As presented in Table I, the expression levels of PD-1 on $\mathrm{CD}^{+}$and $\mathrm{CD}^{+} \mathrm{T}$ cells was positively associated with FIGO stage (Fig. 4) and no association was demonstrated between PD-L1 expression and clinicopathological factors including age, histopathology, FIGO stage, grade of differentiation, lymph node invasion, tumor size, 

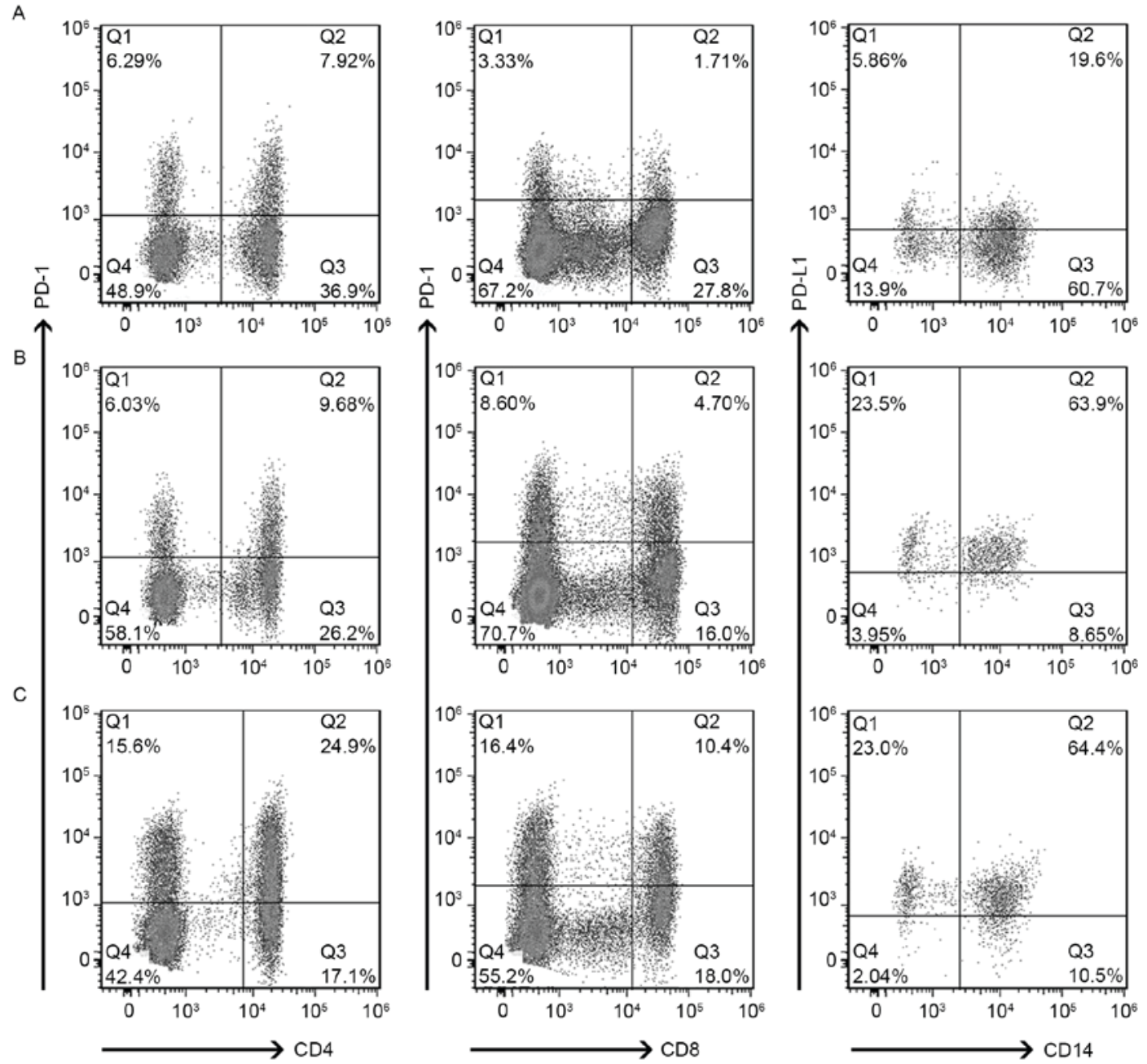

Figure 1. Representative dot plots of PD-1 expression level on peripheral CD4 $4^{+}$and CD8 ${ }^{+}$T-cells and PD-L1 expression on CD14 monocytes in (A) healthy controls, (B) cervical intraepithelial neoplasia and (C) cervical cancer. The lymphocyte and monocyte subpopulation were selected on the basis of forward scatter and side scatter from peripheral blood cells. The percentage of positive cells is indicated in the upper right region. PD-1, programmed death-1; PD-L1, programmed death-ligand 1; CD, cluster of differentiation.

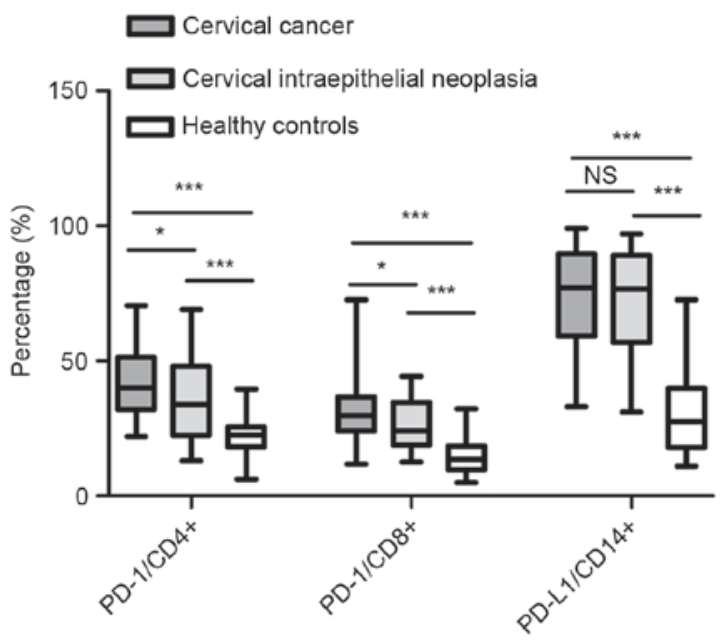

Figure 2. Expression levels of PD-1 and PD-L1 increased on peripheral $\mathrm{T}$ cells and $\mathrm{CD} 14^{+}$monocytes, respectively. Boxes represent the interquartile range and horizontal lines inside each box represent the median. The vertical lines from the ends of each box encompass the extreme data points. Expression level of PD-1 on CD4 ${ }^{+} \mathrm{T}$-cells or $\mathrm{CD} 8^{+} \mathrm{T}$-cells was presented as a percentage. P-values were determined using an unpaired Student's t-test. ${ }^{*} \mathrm{P}<0.05 ;{ }^{* *} \mathrm{P}<0.01 ;{ }^{* * *} \mathrm{P}<0.001$. NS, not significant; $\mathrm{PD}-1$, programmed death-1; PD-L1, programmed death-ligand 1; CD, cluster of differentiation. parametrical invasion and high-risk type of human papillomavirus (HR-HPV) positivity in cancer. In addition, the present study did not reveal any significant association of PD-1/PD-L1 expression level with grade of differentiation and HR-HPV infection in CIN (data not shown).

Expression level of soluble PD-L1. Sequentially, the present study evaluated the expression level of SPD-L1 in the serum of various patient groups and demonstrated that SPD-L1 expression level in patients with cervical cancer $(0.320 \pm 0.015 \mu \mathrm{g} / \mathrm{l})$, patients with CIN $(0.315 \pm 0.016 \mu \mathrm{g} / \mathrm{l})$ and healthy controls $(0.389 \pm 0.023 \mu \mathrm{g} / \mathrm{l})$ were all low level and there was no significant difference between them.

\section{Discussion}

The PD-1 signaling pathway activates second messengers that influence T-cell proliferation, cytokine production and cytolytic function, which serve pivotal roles in immune regulation and immune tolerance (20). This pathway may be a potential immunomodulatory mechanism employed by tumors to subvert the host immune response. Various antibodies have entered 

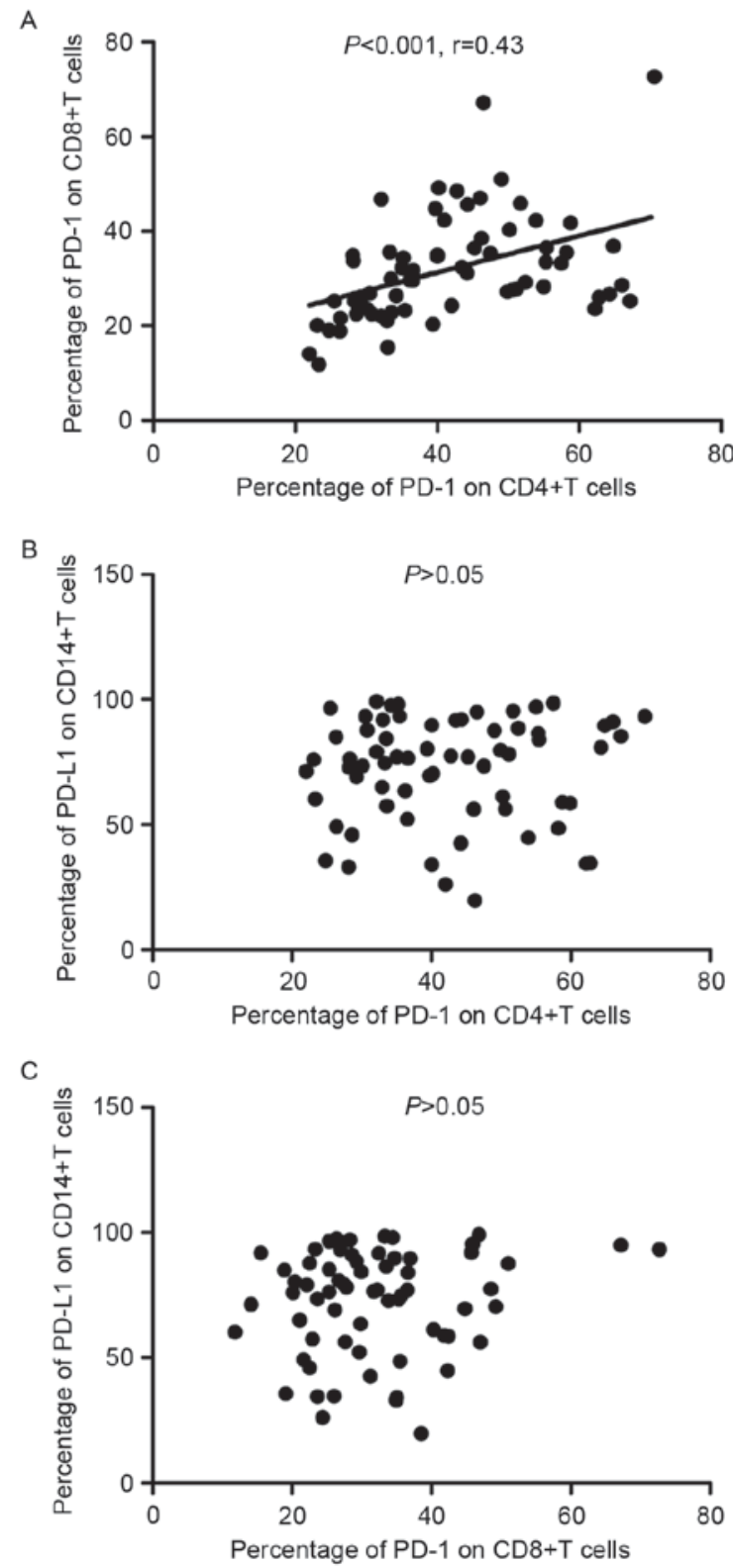

Figure 3. Association between the percentage of (A) PD-1 expressed on $\mathrm{CD}^{+}$ and $\mathrm{CD} 8^{+} \mathrm{T}$ cells, (B) PD- 1 on $\mathrm{CD} 4^{+} \mathrm{T}$ cells and PD-L1 on $\mathrm{CD}^{+} 4^{+}$monocytes and (C) PD-1 on CD8 ${ }^{+} \mathrm{T}$ cells and PD-L1 on monocytes in cervical carcinoma patients. Each dot represented one subject. A total of 66 patients with cervical cancer were included. PD-1, programmed death-1; PD-L1, programmed death-ligand $1 ; \mathrm{CD}$, cluster of differentiation.

clinical trials targeting this pathway and have demonstrated efficacy and objective responses in solid tumors (15). However, studies investigating the PD-1 signaling pathway, particularly on the role of the pathway in the peripheral immune system, in cervical cancer remain limited. The present study first focused on the expression level of PD-1 on peripheral T cells and PD-L1 on monocytes and the expression level of soluble PD-L1 in patients with cervical carcinoma, and further explored their correlations with clinicopathological parameters. The results provide evidence that $\mathrm{PD}-1 / \mathrm{PD}-\mathrm{L} 1$ is involved in the development of cervical cancer and CIN.

PD-1 is classified as a member of the CD28 co-stimulatory receptor super-family, which is expressed on activated $\mathrm{T}$ and B lymphocytes and interacts with its ligands, PD-L1 and

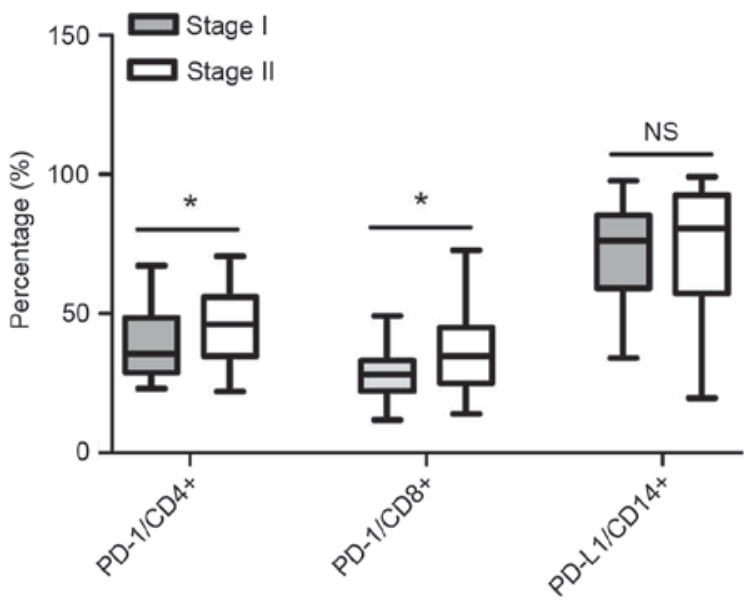

Figure 4. Percentage of PD-1 expressed on $\mathrm{CD}^{+}$and $\mathrm{CD}^{+} \mathrm{T}$ cells and $\mathrm{PD}-\mathrm{L} 1$ on $\mathrm{CD}_{1}{ }^{+}$monocytes in patients with cervical cancer with various tumor stages. Boxes represent the interquartile range and horizontal lines inside each box represent the median. The vertical lines from the ends of each box encompass the extreme data points. A total of 66 patients with cervical cancer were included; 35 patients were stage I and 31 patients were stage II. * $\mathrm{P}<0.05$. NS, not significant; PD-1, programmed death-1; PD-L1, programmed death-ligand $1 ; \mathrm{CD}$, cluster of differentiation.

PD-L2 (5). There is accumulating evidence indicating that upregulation of PD-1 expression on $\mathrm{CD} 4^{+} \mathrm{T}$ cells and $\mathrm{CD} 8^{+}$ $\mathrm{T}$ cells is closely associated with numerous types of autoimmune diseases, viral infections and cancer $(10,21,22)$. For example, Wang et al (21) revealed that expression levels of PD-1 on circulating $\mathrm{T}$ cells were elevated in patients with systemic lupus erythematosus and was associated with the production of anti-self-antibodies. Su et al (22) also demonstrated that proportions of $\mathrm{PD}-1$ expression on $\mathrm{CD} 4^{+}$or $\mathrm{CD} 8^{+} \mathrm{T}$ cells were significantly increased in the patients with cancer compared with the controls, indicating that impaired cellular immune function may contribute to chronic $\mathrm{HCV}$ infection. Previous studies have revealed that PD-1 expression level is upregulated on peripheral $\mathrm{T}$ cells in ovarian and pancreatic cancer $(10,11)$. The present study first demonstrated that PD-1 expression levels on $\mathrm{CD}^{+}$and $\mathrm{CD} 8^{+} \mathrm{T}$ cells were significantly elevated in samples from patients with cancer and CIN compared with in HCs (Fig. 2), indicating a non-redundant role of PD-1 in the pathogenesis of cervical carcinoma and CIN. This important finding suggested that PD-1 expression on T cells may be further exploited as a diagnostic test in the management of cervical lesions.

Previous studies suggested that the expression level of PD-1 on T cells may be positively correlated with disease progression of gastric cancer (12) and chronic lymphocytic leukemia (23). Consistent with this, the present study revealed that $\mathrm{PD}-1$ expression on $\mathrm{CD}^{+}$and $\mathrm{CD} 8^{+} \mathrm{T}$ cells was significantly higher in cervical patients with stage II compared with stage I (according to FIGO stage), suggesting that PD-1 may also act as an indicator of disease progression in cervical cancer. Yang et al (24) reported that PD-1 expression on cervical $\mathrm{T}$ cells was associated with HR-HPV positivity and increased in parallel with increasing CIN grade. Conversely, the present study did not identify any association between the expression of PD-1 on circulating T cells and HR-HPV infection and CIN grade. One possible explanation may be 
that it is cervical cell-mediated immunity inhibited by the upregulated PD-1 signaling pathway, not peripheral immunity, contributing to the progression of HR-HPV-associated CIN.

Subsequently, the present study investigated the expression level of PD-L1 on circulating monocytes and explored its clinical implications. PD-L1 is expressed in a variety of innate immune cells, including dendritic cells, macrophages and monocytes $(3,5)$. Heeren et al $(25)$ demonstrated that upregulated $\mathrm{CD} 14^{+} \mathrm{PD}-\mathrm{L1}^{+} \mathrm{APC} /$ Treg axis contributed to a switch to a profound immune-suppressive microenvironment in metastatic lymph nodes from patients with cervical cancer, which enabled immune escape. The present study differs from the study by Heeren et al (25) in revealing PD-L1 upregulation on $\mathrm{CD}_{14}{ }^{+}$monocytes in the peripheral blood of patients with cancer and CIN, which is more accessible in the clinical setting. However, the level of PD-L1 expression had no difference between cancer and CIN, and also demonstrated no association with clinical states of both cervical lesions. Thus, increased PD-L1 expression level on circulating CD14 ${ }^{+}$ monocytes may contribute to the pathogenesis of cervical cancer and CIN, but may not be utilized to distinguish benign lesions from malignant tumors or influence the severity of these diseases.

As the distribution of circulating lymphocyte and monocyte subsets significantly changed, the present study analyzed the associations between these subsets in cervical cancer. The results revealed a significantly positive correlation between the expression level of PD-1 on $\mathrm{CD}^{+}$and $\mathrm{CD}^{+} \mathrm{T}$ cells (Fig. 3A), suggesting that the regulation of PD-1 was not cell specific in cancer. Since PD-1 is also expressed on numerous other cell types, including B cells, dendritic cells, NKT cells and on activated monocytes (5), the expression level of PD-1 on these cells in cervical cancer should be investigated in further studies. By contrast, no correlation was identified between PD-1 and PD-L1 expression levels in cancer. It would be useful to explore whether there is a suppressive nature of PD- $\mathrm{L1}^{+}$ monocytes on PD-1 $1^{+} \mathrm{T}$ cells in peripheral blood in cervical cancer, as previously reported in ascites of patients with ovarian cancer (10).

An increased expression level of PD-1 and PD-L1 on circulating immune cells was revealed in the present study, and subsequently detection of the soluble form of these molecules, which acts as an antagonist, blocking PD-1/PD-L1 engagement and increasing the proliferation and cytokine production of T cells, was determined (13). Previous studies have demonstrated that expression levels of sPD-L1 were elevated in lung cancer (14) and aggressive diffuse large B-cell lymphoma (26). Conversely, the present study demonstrated that SPD-L1 inhibitory molecule was expressed at low levels in all analyzed samples of healthy controls and patients. One possible explanation may be that PD-L1 is expressed on only a minority of cervical cancer cells (13), which may not excrete enough PD-L1 resulting in a high expression level of sPD-L1 in serum.

The results of the present study revealed that there are elevated expression levels of PD-1 on T cells and PD-L1 on monocytes in peripheral blood of cervical and CIN patients, and proportions of $\mathrm{PD}-1$ on $\mathrm{CD}^{+}$and $\mathrm{CD} 8^{+} \mathrm{T}$ cells were positively associated with tumor stages reflecting the severity of cancer. These novel results suggested that PD-1 expression on $\mathrm{T}$ cells and PD-L1 on $\mathrm{CD} 14^{+}$monocytes may be potent predicting biomarkers and may indicate usefulness of alternative immunological therapeutic strategies using PD-1 axis inhibitors for cervical cancer and CIN.

A number of limitations should be noted. The overall sample size of the present study is relatively small and the changes of PD-1/PD-L1 expression levels over time following treatments including operation, radiotherapy and chemotherapy, were not evaluated. Another limitation is that the present study was not designed to predict the mortality rate of cervical carcinoma. Thus, further larger prospective longitudinal studies are required.

\section{Acknowledgements}

This project is subject to The Second Affiliated Hospital of Soochow University preponderant clinical disciplinary group funding (grant no. XKQ2015007) and Jiangsu Province's maternal and child health research projects (grant no. F201617).

\section{References}

1. Parkin DM, Bray F, Ferlay J and Pisani P: Global cancer statistics,2002. CA Cancer J Clin 55: 74-108, 2005.

2. Nedergaard BS, Ladekarl M, Nyengaard JR and Nielsen K: A comparative study of the cellular immune response in patients with stage IB cervical squamous cell carcinoma Low numbers of several immune cell subtypes are strongly associated with relapse of disease within 5 years. Gynecol oncol 108: 106-111, 2008.

3. Zou W and Chen L: Inhibitory B7-family molecules in the tumour microenvironment. Nat Rev Immunol 8: 467-477, 2008.

4. Barber DL, Wherry EJ, Masopust D, Zhu B, Allison JP, Sharpe AH, Freeman GJ and Ahmed R: Restoring function in exhausted CD8 T cells during chronic viral infection. Nature 439: 682-687, 2006.

5. Keir ME, Butte MJ, Freeman GJ and Sharpe AH: PD-1 and its ligands in tolerance and immunity. Annu Rev Immunol 26: 677-704, 2008

6. Topalian SL, Hodi FS, Brahmer JR, Gettinger SN, Smith DC McDermott DF, Powderly JD, Carvajal RD, Sosman JA, Atkins MB, et al: Safety, activity and immune correlates of anti-PD-1 antibody in cancer. N Engl J Med 366: 2443-2454, 2012.

7. Ohigashi Y, Sho M, Yamada Y, Tsurui Y, Hamada K, Ikeda N, Mizuno T, Yoriki R, Kashizuka H, Yane K, et al: Clinical significance of programmed death-1 ligand-1 and programmed death-1 ligand-2 expression in human esophageal cancer. Clin Cancer Res 11: 2947-2953, 2005.

8. Ghebeh H, Mohammed S, Al-Omair A, Qattan A, Lehe C, Al-Qudaihi G, Elkum N, Alshabanah M, Bin Amer S, Tulbah A, et al: The B7-H1 (PD-L1) T lymphocyte-inhibitory molecule is expressed in breast cancer patients with infiltrating ductal carcinoma: Correlation with important high-risk prognostic factors. Neoplasia 8: 190-198, 2006.

9. Thompson RH, Kuntz SM, Leibovich BC, Dong H, Lohse CM, Webster WS, Sengupta S, Frank I, Parker AS, Zincke H, et al: Tumor B7-H1 is associated with poor prognosis in renal cell carcinoma patients with long-term follow-up. Cancer Res 66: 3381-3385, 2006.

10. Maine CJ, Aziz NH, Chatterjee J, Hayford C, Brewig N, Whilding L, George AJ and Ghaem-Maghami S: Programmed death ligand-1 over-expression correlates with malignancy and contributes to immune regulation in ovarian cancer. Cancer Immunol Immunother 63: 215-224, 2014.

11. Komura T, Sakai Y, Harada K, Kawaguchi K, Takabatake H, Kitagawa H, Wada T, Honda M, Ohta T, Nakanuma $Y$ and Kaneko S: Inflammatory features of pancreatic cancer highlighted by monocytes/macrophages and CD4+ T cells with clinical impact. Cancer Sci 106: 672-686, 2015. 
12. Saito H, Kuroda H, Matsunaga T, Osaki T and Ikeguchi M: Increased PD-1 expression on CD4+ and CD8+ T cells is involved in immune evasion in gastric cancer. J Surg Oncol 107: 517-522, 2013

13. Zhao J, Pan X, Xing Y, Lu M, Chen Y and Shi M: Effects of soluble programmed death ligand 1 on regulating the proliferation of T lymphocytes and its mechanism. Zhonghua Yi Xue Za Zhi 95: 449-452, 2015 (In Chinese).

14. Xing YF, Zhang ZL, Shi MH, Ma Y and Chen YJ: The level of soluble programmed death-1 in peripheral blood of patients with lung cancer and its clinical implications. Zhonghua Jie $\mathrm{He} \mathrm{He} \mathrm{Hu}$ Xi Za Zhi 35: 102-106, 2012 (In Chinese).

15. Gangadhar TC and Salama AK: Clinical applications of PD-1-based therapy: Afocus on pembrolizumab (MK-3475) in the management of melanoma and other tumor types. Onco Targets Ther 8: 929-937, 2015.

16. Karim R, Jordanova ES, Piersma SJ, Kenter GG, Chen L, Boer JM, Melief CJ and van der Burg SH: Tumor-expressed B7-H1 and B7-DC in relation to PD-1+ T-cell infiltration and survival of patients with cervical carcinoma. Clin Cancer Res 15: 6341-6347, 2009.

17. Heeren AM, Kenter GG, Jordanova ES and de Gruijl TD: CD14 macrophage-like cells as the linchpin of cervical cancer perpetrated immune suppression and early metastatic spread: A new therapeutic lead? Oncoimmunology 4: e1009296, 2015.

18. FIGO Committee on Gynecologic Oncology: FIGO staging for carcinoma of the vulva, cervix and corpus uteri. Int J Gynaecol Obstet. 125: 97-98, 2014

19. Moniuszko M, Kowal K, Zukowski S, Dabrowska M and Bodzenta-Lukaszyk A: Frequencies of circulating CD4+CD25+CD127low cells in atopics are altered by bronchial allergen challenge. Eur J Clin Invest 38: 201-204, 2008.

20. Riley JL: PD-1 signaling in primary T cells. Immunol Rev 229 114-125 2009.
21. Wang Y, Xie C, Sun M, Chai J, Zhou Y, Chen Y, Tang J and Li B: Expression and significance of PD-1 on CD4 (+); and CD8 (+); T cells from the peripheral blood of patients with systemic lupus erythematosus. Xi Bao Yu Fen Zi Mian Yi Xue Za Zhi 29: 962-965, 2013 (In Chinese).

22. Su SS, He H, Kong LB, Zhang YG, Zhao SX, Wang RQ, Zheng HW, Sun DX, Nan YM and Yu J: Regulatory phenotype, PD-1 and TLR3 expression in T cells and monocytes from HCV patients undergoing antiviral therapy: A randomized clinical trial. PLoS One 9: e93620, 2014.

23. Rusak M, Eljaszewicz A, Bolkun L, Łuksza E, Łapuć I, Piszcz J, Singh P, Dąbrowska M, Bodzenta-Łukaszyk A, Kłoczko J and Moniuszko M: Prognostic significance of PD-1 expression on peripheral blood CD4+ T cells in patients with newly diagnosed chronic lymphocytic leukemia. Pol Arch Med Wewn 125: 553-559, 2015.

24. Yang W, Song Y, Lu YL, Sun JZ and Wang HW: Increased expression of programmed death (PD)-1 and its ligand PD-L1 correlates with impaired cell-mediated immunity in high-risk human papillomavirus-related cervical intraepithelial neoplasia. Immunology 139: 513-522, 2013.

25. Heeren AM, Koster BD, Samuels S, Ferns DM, Chondronasiou D, Kenter GG, Jordanova ES and de Gruijl TD: High and interrelated rates of $\mathrm{PD}-\mathrm{L1}^{+} \mathrm{CD} 14^{+}$antigen-presenting cells and regulatory $\mathrm{T}$ cells mark the microenvironment of metastatic lymph nodes from patients with cervical cancer. Cancer Immunol Res 3: 48-58, 2015.

26. Rossille D, Gressier M, Damotte D, Maucort-Boulch D, Pangault C, Semana G, Le Gouill S, Haioun C, Tarte K, Lamy T, et al: High level of soluble programmed cell death ligand 1 in blood impacts overall survival in aggressive diffuse large B-Cell lymphoma: Results from a French multicenter clinical trial. Leukemia 28: 2367-2375, 2014. 